\title{
Failure Predictive Models for Pipelines Through Neutron Diffraction- Based Stress Assessment Tools
}

\author{
P. Genta ${ }^{1}$ and M. Rogante ${ }^{*}, 2$ \\ ${ }^{1}$ Saudi Aramco, Pipelines Specialist Unit, Dhahran 31311, P. O. Box 9484, Saudi Arabia \\ ${ }^{2}$ Rogante Engineering Office, Contrada San Michele, 61, P. O. Box 189, 62012 Civitanova Marche, Italy
}

\begin{abstract}
This paper discusses the current problems of assessing the pipeline integrity from an identification of the causal factors associated to various pipeline failure mechanisms and damages, such as corrosion, SCC, buckling, soil movement, and fatigue. The paper explains, furthermore, how emerging applications of Neutron Diffraction and Small Angle Neutron Scattering techniques can be carried out to assess residual stress and microstructural characterization in pipelines. The benefits of the mentioned techniques are also discussed, in determining the pipeline real conditions and building forecast fracture models, providing end-users with essential support to effectively manage pipeline rehabilitation and maintenance plans.
\end{abstract}

\section{INTRODUCTION}

The question of guaranteeing pipeline structural integrity is based on the ability of the pipeline operators in maintaining a low likelihood of failures, as well as operation and maintenance costs staying under control. The capability of the pipeline operator in preventing failures through the use of effective predictive models, along with appropriate inspection, is determinant in retaining a low failure rate level throughout the expected pipeline life.

In pipelines, the reliability of the innumerable welded joints involved, as still the presence of micro-cracks due to the welding process, can establish a yielding of the whole structure. An accurate method to assess residual stress (RS) in pipelines, in this case, is essential in achieving the desired safety and reliability levels.

Knowledge of RS status and other micro-structural factors (e.g., inhomogeneities, micro-voids, precipitates) present in pipelines can help "debugging" the processes of selecting pipe manufacturers, specifying quality of materials, establishing safe operating pressures as well as better planning maintenance and rehabilitation programs.

RS in pipelines can arise, in general, from the material's history, production, ground movement and in-service damage. Extrusion, filament winding, thermal treatment and welding processes are able to induce RS, which subsist without any external loading being applied to the material.

To estimate the real total stress existing when a material is subjected to external loads, consequently, the RS state should be taken into account. Some components of said combined total stress may exceed a particular design stress limit for the considered material, involving, thus, the risk of an early structural failure.

\footnotetext{
*Address correspondence to this author at the Rogante Engineering Office, Contrada San Michele, 61, P. O. Box 189, 62012 Civitanova Marche, Italy; Tel: +39 0733 775248; Fax: +39 0733 1941197;

E-mail: main@roganteengineering.it
}

RS represents, consequently, a peculiar problem in pipelines. Knowledge of spatial and directional RS distribution in pipelines becomes fundamental to determine their influence on the involved material.

The assessment of RS levels through neutron diffraction (ND) allows revealing the hidden cause-effect relationships between the current condition of a given pipeline material under study and its potential future failure modes under operating conditions. The understanding of such relationships permits predicting which types of failure modes are likely to occur and the pipeline material resistance to crack propagation under operating conditions. Building a valid failure predictive model, however, requires taking into consideration valid methods of material samples collection, cataloguing and data analysis, whose description exceeds the purpose of this paper.

The information obtained by the ND tool should be completed by small angle neutron scattering (SANS), which provides additional data to characterize types, amounts and size of defects. SANS allows micro-beam scan and detecting nano-pores (nano-cracks) in the sample materials. SANS analysis of samples exposed to different mechanical loads, in particular, provides information on the nanoscopic and microscopic development of defects and its relation to applied stress: from dislocations to voids and cracks.

The comparative analysis between the SANS cross sections for fresh prepared and aged samples provides also information on the size distribution and concentration of new defects induced by the materials' treatments [1,2].

\section{EXPERIMENTAL PROCEDURES}

\section{Residual Stresses Determination by Neutron Diffraction}

In the strain measurement, a collimated neutron beam (having a wavelength $\lambda$ ) is diffracted by a polycrystalline sample, then it passes through a second collimator and reaches the detector. Both collimator slits define the investigated volume (Fig. 1), whose cross section, normally, can be as small as $1 \times 1 \mathrm{~mm}^{2}$ or, in singular cases, smaller. 


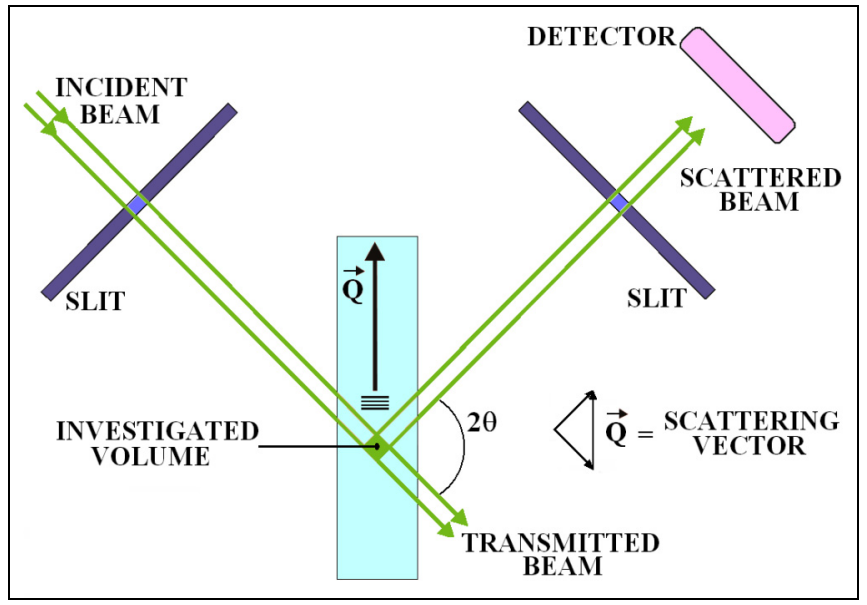

Fig. (1). Scheme of the strain measurement by Neutron Diffraction.

The Bragg's law:

$n \lambda=2 d_{h k l} \sin \theta$

(the integer $n$ being the diffraction order, $2 \theta$ the ample take off angle related to the maximum of the Bragg diffracted intensity peak and $h k l$ the Miller's indices of the investigated lattice planes) allows determining the interplanar distance $d_{h k l}$. The corresponding lattice strain is given by the relation:

$\varepsilon_{h k l}=\frac{d_{h k l}-d_{0}}{d_{0}}$

where $d_{0}$ is the $h k l$ interplanar distance (lattice spacing) in a stress-free reference material. The analysis of tri-axial stress states, in particular, requires accurate values of the unstressed lattice spacing. A strainless sample of the material avoids systematic errors in the $d_{0}$, hence in the strain value. Various experimental and analytical methods exist for the determination of $d_{0}$, which are discussed in [3]. The representative geometry of diffraction related to pipes (tri-axial stress states) is shown in Fig. (2).

The RS values can be obtained, thus, by knowing the elastic constants of the considered material and using the relations:

$$
\begin{aligned}
& \sigma_{x x}=\frac{E}{(1+v)(1-2 v)}\left[(1-v) \varepsilon_{x x}+v\left(\varepsilon_{y y}+\varepsilon_{z z}\right)\right] \\
& \sigma_{y y}=\frac{E}{(1+v)(1-2 v)}\left[(1-v) \varepsilon_{y y}+v\left(\varepsilon_{x x}+\varepsilon_{z z}\right)\right] \\
& \sigma_{z z}=\frac{E}{(1+v)(1-2 v)}\left[(1-v) \varepsilon_{z z}+v\left(\varepsilon_{y y}+\varepsilon_{x x}\right)\right]
\end{aligned}
$$

where $\sigma_{x x}, \sigma_{y y}$ and $\sigma_{z z}$ are the principal stresses, $E$ is the Young's modulus and $v$ is the Poisson's ratio in an elastically isotropic model.

Investigation of micro-strains is based on the analysis of the shape of broadened diffraction profiles. For a full treatment of the theoretical bases, see [3-7].

RS measurements by ND present the advantages of being non-destructive and providing information with high statistical exactness, due to the averaging over a macroscopic sample volume. The specimen can be investigated various times after more exercise or heat-treatments, and the small absorption of neutrons, often allows the measurement of centimetre thick materials. The same measurement can be performed on pipeline specimens before and after heat treatment or welding process, and/or after different exercise periods; points of the pipe can be investigated at different depths. Deformation tests can be also carried out in situ at the neutron beam, enabling both tensile and compressive tests up to a certain maximum loading.

\section{Micro- and Nano-Structural Investigations by Small An- gle Neutron Scattering}

SANS technique allows characterizing materials in the nano-scale range $(10 \AA-1000 \AA)$, and it also presents the advantages as mentioned concerning ND.

The thermal treatment due to the welding process, as known, produces the growth of some inclusions (precipitates); SANS allows obtaining their characteristics (number

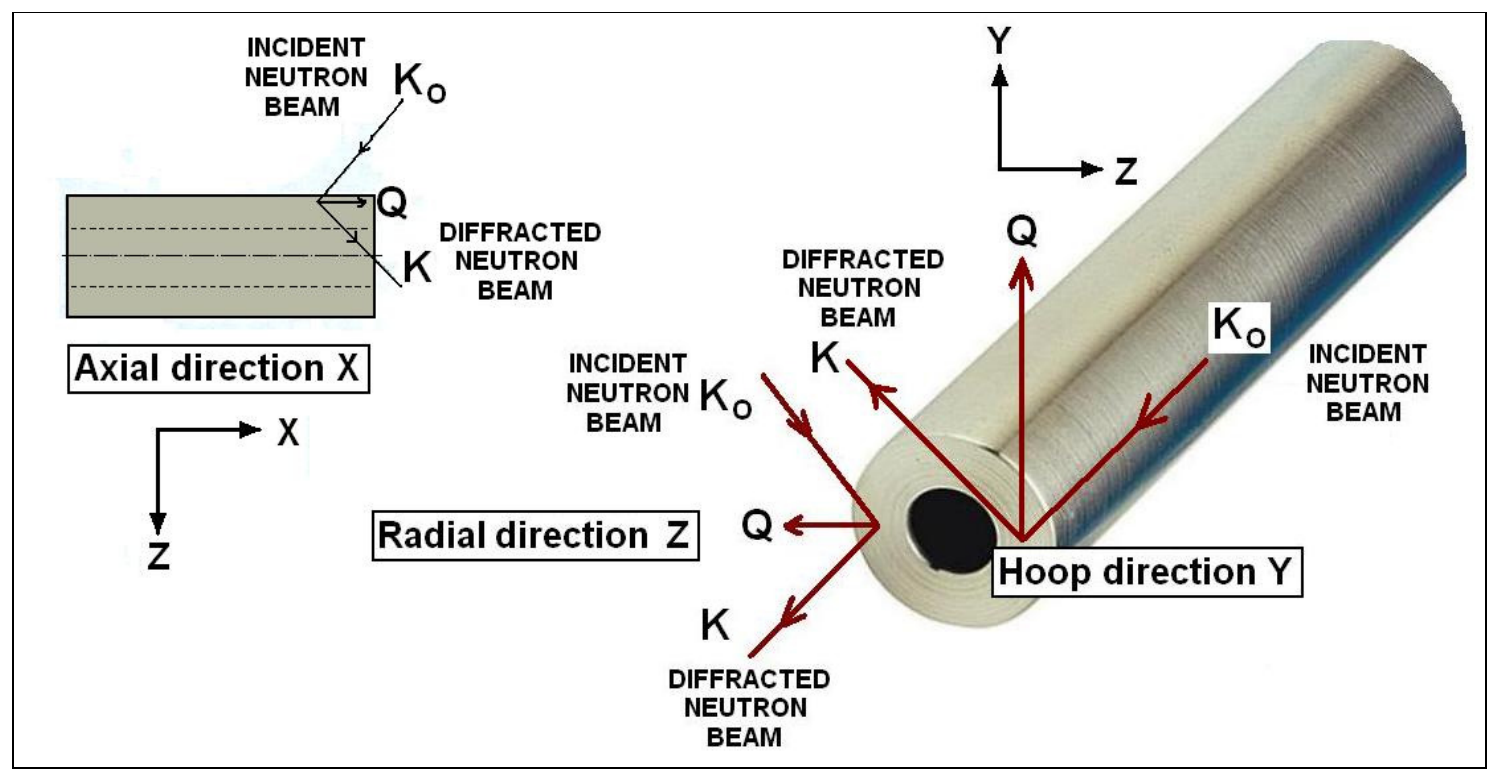

Fig. (2). Representative geometry of diffraction related to pipes. 
and size distribution), by knowing the chemical nature of precipitates (e.g., carbides, etc.). A sample can be investigated from the original material - before the exercise -, other samples after the exercise, including welded part, in order to check the microstructural changes (e.g., nano-defects and voids). For a full treatment of the theoretical bases, see [712].

\section{OBTAINABLE RESULTS AND FAILURE PREDIC- TIVE MODELS}

Fig. (3) represents hoop RS determined by ND in a 2.25 Cr1Mo ferritic arc welded pipe before and after relaxation heat treatment ( $5 \mathrm{~mm}$ depth). The gap between the RS values self-explains the resulting deviation trend between heat treated and not heat treated material.

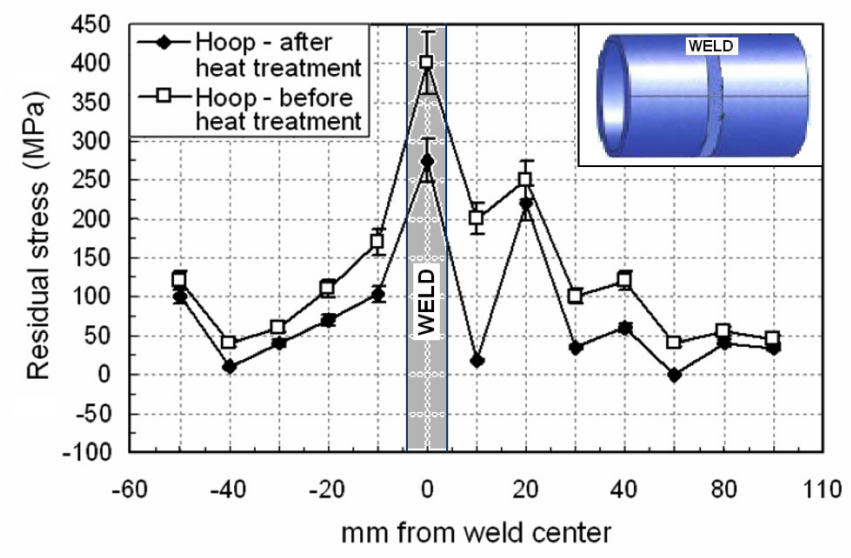

Fig. (3). Hoop RS (5 mm depth) determined by Neutron Diffraction in a $2.25 \mathrm{Cr} 1 \mathrm{Mo}$ ferritic arc welded pipe before and after relaxation heat treatment.

In the case of thermal-related failures, the predictive model's objective is to characterize the measured deviations between RS curves for the different installation and operating conditions of the studied samples. The gradient of the difference between RS curves along with other factors such as cycling fatigue caused by operating conditions needs to be considered as well. The stress failure main modes outline, in general, can be represented in Table $\mathbf{1}$.

Synergic effects of both thermal/metallurgical and mechanical related stress exist, in the case of welded pipes, which can enhance the ageing process of the considered component. The failure forecasting model needs to be built taking into account the combined effects of the various stress failure present modes and their causal factors.

Concerning SANS, application examples are provided in $[6,7]$ and [13]. SANS provides a rich information on the metal and welded joints nano-structure, and the obtained results are useful to predict joint quality changes.

The analysis of precipitates gyration mean radius, concentration, metal carbide interface area per unit volume, and volume fraction, can help determine the behaviour of the exercised material (exposed to thermal and mechanical stresses); said parameters, in fact, are representative of the degradation level of materials, being also relevant to the determination of root causes of stress. The particles present in the material, e.g., as a consequence of thermal treatment during the manufacturing - heating at high temperatures (espe- cially for a relatively long time) - are partially dissolved and the solid solution becomes saturated. The precipitates, by cooling, grow from the saturated solution. The particles growth caused by high temperature levels can induce a microstructure coarsening and the precipitates growth. Evaluation of shape and size of such precipitates, thus, can be particularly useful to locate the areas of maximum thermal alteration and estimate the velocity of the said alteration.

Table 1. Stress Failure Modes

\begin{tabular}{|c|c|}
\hline \multirow{3}{*}{ MECHANICAL RELATED GROUP } & $\begin{array}{l}\text { MECHANICAL } \\
\text { PROCESSING, e.g.: } \\
-\quad \text { turning } \\
-\quad \text { milling } \\
-\quad \text { grinding }\end{array}$ \\
\hline & $\begin{array}{l}\text { PLASTIC } \\
\text { DEFORMATION, e.g. } \\
-\quad \text { rolling } \\
-\quad \text { moulding } \\
-\quad \text { drawing }\end{array}$ \\
\hline & $\begin{array}{l}\text { MECHANICAL } \\
\text { TREATMENTS, e.g.: } \\
\text { - } \quad \text { shot peening } \\
-\quad \text { hammering }\end{array}$ \\
\hline \multirow{3}{*}{$\begin{array}{l}\text { THERMAL/METALLURGICAL } \\
\text { RELATED GROUP }\end{array}$} & WELDING PROCESS \\
\hline & $\begin{array}{l}\text { THERMAL } \\
\text { TREATMENTS, e.g.: } \\
\text { - } \quad \text { hardening } \\
-\quad \text { cementing } \\
-\quad \text { nitriding }\end{array}$ \\
\hline & COATING PROCESS \\
\hline
\end{tabular}

A welded joint can be scanned by a thin neutron beam, to obtain the SANS data for base and welded metal. The following results are reported, e.g., concerning a SANS investigation of a sample cut out from a plate of base metal (100 $\mathrm{mm}, 08 \mathrm{H} 18 \mathrm{~N} 10 \mathrm{~T}$ austenite stainless steel, SU standard) and welded by the wire in electric arc. Base metal and welded joint have been thermally treated, cooling down in water from the initial temperature of $1050^{\circ} \mathrm{C}$. Three fractions of particles were detected by the SANS investigation, with gyration radii: $R_{g 1} \sim 20 \mathrm{~nm}, R_{g 2} \sim 9 \mathrm{~nm}$ and $R_{g 3} \leq 1 \mathrm{~nm}$ (point like defects). The amount of these defects in the considered base metal, as shown in Fig. (4), resulted larger by factor 5, as compared to welded metal.

The observed scattering is attributed to $\mathrm{Cr}_{23} \mathrm{C}_{6}$ precipitates, and their content in base metal $\left(C_{B}=0.1 \%\right.$ vol. $)$ corresponds to the amount of carbon $\left(C_{C B}=0.05 \% \mathrm{wt}\right)$ that is close to its total concentration in steel $\left(C_{C \max }=0.07 \% \mathrm{wt}\right.$.). The concentration of precipitates in welded metal, on the other hand, is lower $\left(C_{W}=0.02 \% \mathrm{vol}.\right)$, and only a small amount of carbon $(0.01 \% \mathrm{wt}$.$) is precipitated [14].$

The main problems of materials' strength as well are related to welded metals, whose fracture risk appears much more elevated than that in the base metal. The higher risk of joints' fracture is due to mechanical stresses (non-uniform) and other factors evoking aging (thermal treatment, conse- 
quent thermal/related stress, fatigue, corrosion). Current concepts of metal fracture, together with welded joints, are essentially based on the optical and electron microscopy data of surface structures or defects in thin slices. Several researches from the field of fractography, in the past, have been directed towards the Scanning Electron Microscopy (SEM) in order to quantify the features in the non-planar fracture surface $[15,16]$. The important characteristics that unlock these quantitative data are the true fracture surface areas. Various experimental procedures have been proposed to obtain the surface area (e.g., the analysis of the resulting profiles related to the fracture surface). The fractal properties of profiles and surfaces have been investigated as well, as a part of the fracture studies. Fractal dimensions resulting from the said nano-scale structures analyses appear normally applicable to natural irregular non-planar surfaces. The notion of fractals has been developed by Mandelbrot, who underlined the numerous natural structures that appear self-similar [17]. Two major classes of fractal structures are present: aggregated clusters of small particles (volume fractals), and systems with irregular interfaces and grain boundaries (surface fractals). SANS measurements allow either verifying the fractal nature of structures, or finding the fractal dimensions [14].

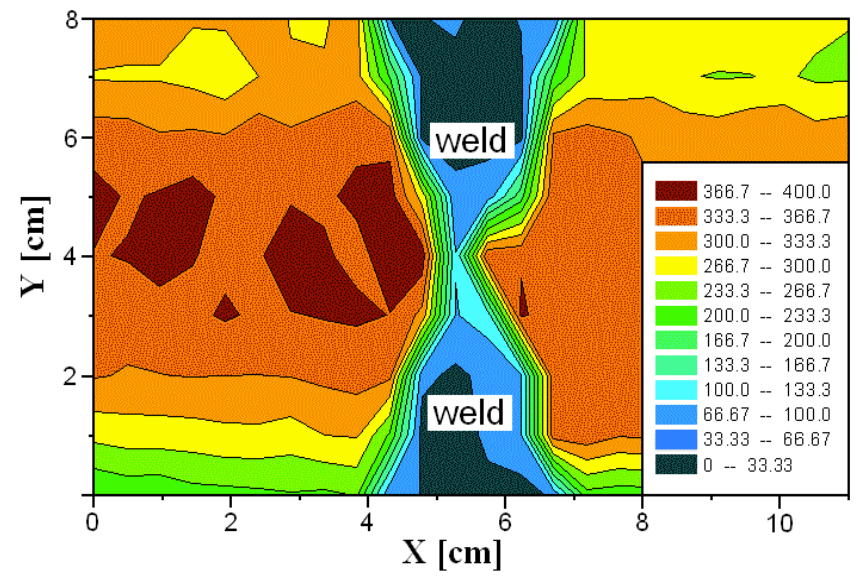

Fig. (4). SANS-scan over 08H18N10T austenite stainless steel welded and base metal: forward cross section $\mathrm{I}_{01}\left(\right.$ per $\left.\mathrm{cm}^{3}\right)$ for large defects $\left(\mathrm{R}_{\mathrm{g} 1} \sim 20 \mathrm{~nm}\right)$. The colour scale is in units of $\mathrm{cm}^{-1}$.

The parameters typically adopted by the pipeline operator to ensure safe operations throughout the plant life, present a considerable lack of data, and the outstanding of the involved materials mechanical properties is strictly depending on precipitates morphology and applied heat treatment. The morphology is conventionally studied by Transmission Electron Microscopy (TEM), but this and other materials science standard methods do not consent to obtain a complete characterization of the microstructure. The precursory adoption of ND and SANS techniques permits controlling the microand nano-structure of the pipeline materials, improving significantly the existing data set thanks to the availability of new complementary essential parameters. Table 2 shows the complementary fundamental parameters that help understand and ultimately predict the degradation of materials, its possible fracture and lifetime. These parameters are determined on real samples, and supplied by a neutron-based investigation for the pipeline control: $\sigma_{x}, \sigma_{y}, \sigma_{z}$ (RS in the material bulk along the main directions, by $\mathrm{ND}$ ), $\mathrm{R}_{\mathrm{G}}$ (gyration mean radius of precipitates, by SANS), C (precipitates concentration, by SANS), $S_{T}$ (metal-precipitate interface area per unit volume, by SANS), and $V_{F}$ (precipitates volume fraction, by SANS).

\section{Table 2. Parameters Completion for Pipeline Control}

\begin{tabular}{|c|c|c|c|}
\hline \multicolumn{2}{|c|}{$\begin{array}{l}\text { Hardness data } \\
\text { HB, HR, Hv, etc. }\end{array}$} & \multirow{12}{*}{$\begin{array}{c}\text { Neutron } \\
\text { Diffraction } \\
\text { and } \\
\text { SANS } \\
\downarrow \\
\qquad \bullet \rightarrow\end{array}$} & $\begin{array}{l}\text { Hardness data } \\
\mathrm{HB}, \mathrm{HR}, \mathrm{HV} \text {, etc. }\end{array}$ \\
\hline \multicolumn{2}{|c|}{ TEM, SEM data } & & TEM, SEM data \\
\hline \multicolumn{2}{|l|}{ X-ray data } & & X-ray data \\
\hline \multicolumn{2}{|c|}{ Resilience $\left(\mathrm{U}_{\mathrm{r}}\right)$} & & Resilience $\left(\mathrm{U}_{\mathrm{r}}\right)$ \\
\hline \multicolumn{2}{|c|}{ other standard data } & & other standard data \\
\hline \multirow{7}{*}{$\begin{array}{l}\text { lack of } \\
\text { essential } \\
\text { parameters }\end{array}$} & $?$ & & $\sigma_{\mathrm{x}}$ \\
\hline & $?$ & & $\sigma_{\mathrm{y}}$ \\
\hline & $?$ & & $\sigma_{\mathbf{z}}$ \\
\hline & $?$ & & $\mathbf{R}_{\mathrm{G}}$ \\
\hline & $?$ & & C \\
\hline & $?$ & & $\mathbf{S}_{\mathrm{T}}$ \\
\hline & $?$ & & $\mathbf{V}_{\mathbf{F}}$ \\
\hline
\end{tabular}

The proposed failure forecasting model for pipelines will be able to calculate RS in the material bulk and material remaining life-time by utilizing fairly simple pattern matching techniques of actual pipeline data against the previously identified patterns. The model data sources are mainly the pipeline design data and those obtained from ND and SANS investigations.

The model consents to predict the considered material behaviour under different possible scenarios. If the mechanical stress conditions continue as present, e.g., the material will suffer said defect; the cycling fatigue process in presence of thermal-related RS, otherwise, can cause a material fracture if the cycling conditions continue.

The remaining life can be determined, in addition, by characterizing the gap between stress status estimates and maximum permissible stress values for the considered material under different scenarios. The identification of failures probable causal factors, and the ability to provide the user with alerts to whether prevent, eliminate such causal factors, or otherwise mitigate the resulting problems, represent further essential features of the failure forecasting model.

Material, operating, installation and environmental conditions embody the input of the proposed predictive model, while the output is represented by the RS status and the remaining life evaluation, the probable failure mode and the recommended measures.

The said model considers: material conditions, including material composition, measured wall thickness, corrosion level, presence and amount of welded joints; operating conditions, including presence of applied forces and its magnitude, fluid pressure, historical accumulated stress (default value as a function of time), fluid properties, corrosion inhibitor chemicals, presence of mechanical vibration and its magnitude; installation conditions, including depth of burial, soil load, coating type and eventual cathode protection. Envi- 
ronmental conditions are considered as well, including seismic level, soil type, rain, washouts and ambient temperature maximum and minimum values.

The model, finally, can consists of a relational database formed by a collection of catalogued material parameters obtained from ND and SANS techniques for fresh samples which represent, statistically, the population of pipelines on which the forecasting tool is planned to be utilized. The extended parameters calculated from ND and SANS (e.g., $\sigma_{x}$, $\sigma_{y}, \sigma_{z}, R_{G}, C, S_{T}$ and $\left.V_{F}\right)$ are catalogued along with the conventional TEM and SEM parameters as well as the operating, installation and environmental conditions under which the samples were taken for both fresh and exercised pipe materials. The deviations between fresh and exercised samples are studied and characterized to obtain a set of deviation patterns. As part of the characterization, trend and inflexion points of the curves are recorded and analyzed in order to determine possible failure modes and remaining life.

\section{CONCLUSIONS}

The proposed failure predictive models, being based on nano-scale level investigations, are able to penetrate into the design and development procedure of pipelines. The obtainable results can translate directly into tangible benefits, as follows:

- Improvement material selection, design of operating conditions and procedures, due to the involvement of nano-scale level investigations;

- $\quad$ help to achieve a better quality standard of pipelines, and enhancement of the existing norms and standards related to pipeline manufacturing procedures;

- optimization of material selection and project requirements of the welding processes;

- $\quad$ optimization of the pipe selection wall thickness, taking into account that thinner pipe walls can significantly reduce the involved $\mathrm{RS}$ gradients which are cause of failures. Said optimization can lead to decreasing material thickness and structural weight, with the consequent reduction in installation and materials costs;

- identification of the cost-effective materials, which minimizes the production of $\mathrm{RS}$, increasing product life, reducing stress-related failures and improving the pipelines reliability;

- achievement of a prioritization tool to repair/replace pipelines exposed to corrosion and stress.

Neutron techniques, furthermore, being complementary to other testing methods, can extend their benefits towards the operations of pipelines by revealing hidden cause-effect relationships of pipeline failures and identifying potential weaknesses in the protection systems [18].

\section{REFERENCES}

[1] M. Rogante, "Neutron examination techniques applied to pipelines", Oil Gas J., pp. 59-64, September 2005.

[2] M. Rogante, "The application of neutron examination to the pipeline industry", J. Pipeline Integr., vol. 4, no. 4, pp. 211-218, 2005.

[3] M. Rogante, "The stress-free reference sample: the problem of the determination of the interplanar distance $\mathrm{d}_{0}$ ", Phys. B: Condens. Matter, vol. 276-278, pp. 202-3, 2000.

[4] I. C. Noyan and J.B. Cohen, Residual Stress - Measurement by Diffraction and Interpretation.. Ilschner, N.J. Grant, Eds. B: New York: Springer-Verlag, 1987, p. 276.

[5] B. D. Cullity, Elements of X-ray Diffraction, $2^{\text {nd }}$ ed. AddisonWesley, Reading: USA, 1978, p. 555.

[6] M. Rogante and L. Rosta, "Nanoscale Characterization by SANS and Residual Stresses Determination by Neutron Diffraction Related to Materials and Components of Technological Interest" in SPIE 5824, Opto-Ireland 2005, Nanotechnology and Nanophotonics, W. J. Blau, D. Kennedy and J. Colreavy, Eds. 2005, pp. 294305 .

[7] M. Rogante, "Caratterizzazione, mediante scattering neutronico, di materiali e componenti per l'impiantistica nucleare ed industriale", $\mathrm{Ph} . \mathrm{D}$. thesis, University of Bologna, Italy, 1999.

[8] G. Kádár and L. Rosta, Eds., Lecture Notes on Neutron Scattering, Introductory Course to ECNS'99. Budapest: KFKI-1999-04/E report, 1999.

[9] O. Glatter and O. Kratky, Eds., Small Angle X-ray Scattering. London: Academic Press, 1982.

[10] C. E. Williams, R. P. May and A. Guinier, "A comprehensive treatment - characterization of materials part II", Mater. Sci. Technol., vol. 2B, pp. 611-656, 1994.

[11] H. M. Rietveld, "Line profiles of neutron powder diffraction peaks for structure refinement", Acta Crystallogr., vol. 22, pp. 151-152, 1967.

[12] H. M. Rietveld, "A profile refinement method for nuclear and magnetic structures", J. Appl. Crystallogr., vol. 2, pp. 65-71, 1969.

[13] M. Rogante, "Applicazioni Industriali delle Tecniche Neutroniche", in $1^{\text {st }}$ Italian Workshop for Industry "Industrial Applications of Neutron Techniques", Civitanova Marche, Italy, 12-14 June 2008, M. Rogante, Ed. 2008, pp. 40-120.

[14] M. Rogante, F. G. Cesari and V. T. Lebedev, "Defectoscopy and perspectives related to metallic materials adoptable in hydrogen storage pressure tanks production", in NATO Advanced Research Workshop on Hydrogen Materials Science and Chemistry of Carbon Nanomaterials ICHMS'2005, T. N. Veziroglu, S. Y. Zaginaichenko, D. V. Schur, B. Baranowski, A. P. Shpak, V. V. Skorokhod and A. Kale, Eds. NATO Security through Science Series, vol. XLI, pp. 135-144, 2007.

[15] K. Wright and B. Karlsson, "Topographic quantification of nonplanar. localized surfaces", J. Microsc., vol. 130/1, pp. 37-51, 1983.

[16] H. E. Exner and M. Fripan, "Quantitative assessment of threedimensional roughness, anisotropy and angular distribution of fracture surfaces", J. Microsc., vol. 138, pp. 161-178, 1985.

[17] B. B. Mandelbrot, The Fractal Geometry of Nature. San Francisco: Freeman, 1982.

[18] M. Rogante and P. Genta, "Neutron diffraction-based tools aid failure forecasting models", Oil Gas J., pp. 56-61, 2008. 